\title{
Prevalence of endometritis diagnosed by vaginal discharge scoring or uterine cytology in dairy cows and herds
}

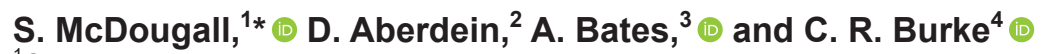 \\ ${ }^{1}$ Cognosco, Anexa, Morrinsville 3300, New Zealand \\ ${ }^{2}$ School of Veterinary Science, Massey University, Palmerston North 4442, New Zealand \\ ${ }^{3}$ Vetlife, Temuka 7920, New Zealand \\ ${ }^{4}$ DairyNZ Ltd., Hamilton 3240, New Zealand
}

\begin{abstract}
Endometritis, diagnosed either by assessing the proportion of nucleated cells that are neutrophils (PMN\%) following cytology of the endometrium or by assessing the degree of purulent material within the vagina (purulent vaginal discharge or PVD score), is prevalent among dairy cows. However, limited data exist as to the degree of variation among herds in the prevalence of endometritis diagnosed by these 2 methods. Thus, we undertook a study involving uterine cytological and vaginal sampling at a median of $41 \mathrm{~d}$ in milk of 1,807 cows from 100 seasonally breeding dairy herds in New Zealand. The optimal cut-point for PMN\% was determined by receiver operator characteristic (ROC) curve analysis using conception to first artificial insemination (AI) as the outcome variable. The prevalence of disease was then calculated at the cow and herd levels, and an estimate of the effect of clustering of cow within a herd was calculated. Reproductive outcomes were collated and associations between endometritis and reproductive outcomes assessed using multivariable models. The optimal PMN\% cut-point was $\geq 2 \%$. The correlation of results for cows within a herd (the intraclass correlation) was 0.03 , which was significant; hence, subsequent modeling accounted for this clustering. The cow-level prevalence of PMN\% $\geq 2 \%$ was $27.0 \%$ [95\% confidence interval (CI): 25.0 to $29.1 \%$ ], whereas the mean withinherd prevalence of PMN\% $\geq 2 \%$ was $27.1 \%$ (95\% CI: 24.7 to $29.6 \%$; range: 5.0 to $63.6 \%$ ), and the prevalence among herds varied significantly. An elevated PMN\% $(\geq 2 \%)$ was significantly associated with a reduction in the proportion of cows conceiving to first AI (45.8 vs. $54.5 \%$ ), a reduced proportion of cows submitted for AI in the first $3 \mathrm{wk}$ of the seasonal breeding program (83.7
\end{abstract}

Received December 11, 2019.

Accepted February 21, 2020.

*Corresponding author: smcdougall@anexafvc.co.nz vs. $89.3 \%$ ), and a lower proportion pregnant in the first 3 (44.4 vs. $55.4 \%)$ and 6 wk $(67.5$ vs. $76.4 \%)$ of the breeding program relative to cows with a low PMN\% (i.e., $<2 \%$ ). A total of $24.6 \%$ of cows had a PVD score $\geq 2$. The herd mean prevalence of PVD score $\geq 2$ was $25.1 \%$ (95\% CI: 22.5 to $27.7 \%$; range: 5.0 to $65.0 \%$ ) and varied significantly among herds. The level of agreement (kappa) between the PVD score and PMN\% was low (16.8\%) and nonsignificant. The effects of PVD score and PMN\% on reproductive outcomes were independent. The within-herd median prevalence of endometritis based on combining both diagnostic tests and using a Bayesian latent class model was $22.9 \%$ (Bayesian $95 \%$ CI: 10.4 to $40.1 \%$ ). We conclude that more than onefifth of dairy cows have endometritis diagnosed either by PMN\% or PVD in seasonal breeding herds when assessed at an average of 41 DIM, which was, on average, $30 \mathrm{~d}$ before the start of the seasonal breeding program. There is large and unexplained variation in prevalence of endometritis among herds. The 2 diagnostic methods were both associated with reproductive outcomes but have low levels of agreement between them and their effects appear to be independent.

Key words: uterine disease, diagnosis, fertility, cytology

\section{INTRODUCTION}

Endometritis is defined as inflammation of the uterus present more than 3 wk after calving (Sheldon et al., 2006). It may be diagnosed by examination of the vaginal contents retrieved using a gloved hand (Sheldon et al., 2002), the Metricheck device (Simcro, Hamilton, New Zealand; McDougall et al., 2007), blood biomarkers (Kaya et al., 2016), or techniques that more directly sample the uterus such as cytology from flushings (Gilbert et al., 2005; Galvão et al., 2009) or cytobrush-collected samples (Kasimanickam et al., 2004a; Barlund et al., 2008), endometrial biopsy (Chapwanya et al., 2010; Bogado Pascottini et al., 2016), the leukocyte esterase 
test (Couto et al., 2013; Denis-Robichaud and Dubuc, 2015a), or bacterial culture (McDougall et al., 2011; Bicalho et al., 2016).

However, a review of the diagnostic techniques (de Boer et al., 2014) has highlighted the fact that none of these tests have been fully validated. Some studies suggest that cytology may be a more sensitive technique than purulent vaginal discharge (PVD; McDougall et al., 2011), whereas others report a stronger association between PVD and subsequent reproductive outcomes (Bicalho et al., 2016). Using Bayesian latent class modeling (LCM), it was demonstrated that the sensitivity of PVD was higher than for percentage neutrophils (PMN\%) at cut-points of $\geq 2$ and $\geq 6 \%$, respectively (Arango-Sabogal et al., 2019). There is no clear consensus as to what is an appropriate cut-point above which a cow is defined as diseased. Optimal PMN\% cut-points have been reported between 6\% (Dubuc et al., 2010) and 10\% (Kasimanickam et al., 2004a) for cows examined at 35 DIM. The PMN\% declines with time postpartum; hence, a higher cut-point is likely more precise for cows examined closer to calving. For example, the optimal PMN\% cut-point was defined as $\geq 6 \%$ when cows were examined at $35 \pm 3$ DIM, and $\geq 4 \%$ when examination occurred at $56 \pm 3$ DIM (Dubuc et al., 2010). Similarly, for pasture-based cows, optimal PMN\% cut-points were found to be $8 \%$ at 21 to 33 DIM, $6 \%$ at 34 to 47 DIM, and $4 \%$ at 48 to 62 DIM (Madoz et al., 2013). For PVD, cut-points of $\geq 2$ (McDougall et al., 2007) or $\geq 4$ (Denis-Robichaud and Dubuc, 2015a) have been suggested as optimal. Part of the variability among studies in defining cut-points is that no gold standard exists for uterine disease. Many studies have optimized cut-points using subsequent reproductive performance (e.g., using confirmed conception to a first postpartum insemination or conception by some defined number of days open as the gold standard; Denis-Robichaud and Dubuc, 2015a) or assumed that one test is a gold standard. Latent class modeling may be used in the absence of a gold standard test (van Smeden et al., 2014). These models provide estimates of sensitivity (Se) and specificity (Sp) without assuming any test is the gold standard. Recently, the Se and Sp for diagnosing reproductive tract health were estimated for leukocyte esterase, cytology, and PVD testing using Bayesian LCM (Arango-Sabogal et al., 2019). The Se and Sp were estimated for the time of diagnosis (i.e., without using some reproductive parameter as the gold standard) and to ensure good stewardship of antimicrobials (Arango-Sabogal et al., 2019). Using various techniques, the prevalence of endometritis varies between $12 \%$ (Barlund et al., 2008) and $>50 \%$ (Gilbert et al., 2005; Hammon et al., 2006; Plöntzke et al., 2010) and varies among herds (McDougall et al., 2007; Prunner et al., 2014; Denis-Robichaud and Dubuc, 2015a). For example, a study involving 779 cows from 38 herds in the United States found that the median herd prevalence was $26.3 \%$ at 40 to 60 DIM but ranged from 4.8 to $52.6 \%$ (Cheong et al., 2011). Similarly, in a study of 28 Canadian herds, the herd-level prevalence of PVD ranged from 4 to $29 \%$, and for endometritis based on PMN\%, from 13 to 64\% (Denis-Robichaud and Dubuc, 2015b). Using a Bayesian LCM-derived cut-point, the within-herd prevalence of reproductive disease in 39 dairy herds when tested at 34 DIM, on average, was 47.9\% (95\% Bayesian CI: 39.0-47.9\%; Arango-Sabogal et al., 2019).

The primary objective of this study was to estimate the cow- and herd-level prevalence of endometritis in New Zealand dairy herds using frequentist and Bayesian LCM analytical approaches.

\section{MATERIALS AND METHODS}

This prospective observational study was conducted following approval of the AgResearch Animal Ethics Committee (application \# 13587; Hamilton, New Zealand).

A convenience sample of 100 pasture-based, springcalving dairy herds, serviced by 1 of 2 veterinary businesses located in the North (Waikato region; $37.8^{\circ} \mathrm{S}$, $175.3^{\circ} \mathrm{E}$ ), and South (Canterbury region; $43.8^{\circ} \mathrm{S}$, $\left.171.2^{\circ} \mathrm{E}\right)$ Islands of New Zealand, were enrolled. Cows were fed predominantly on ryegrass (Lolium perenne) and white clover (Trifolium repens) pasture. Supplementary feeding with, for example, palm kernel expeller, maize silage, or pasture silage occurred depending on farm management.

A 2-stage sampling process was used (Farver, 1987; Akhtar et al., 1988; Dohoo et al., 2003); that is, herds were selected from among those herds serviced by 2 veterinary practices, and then cows within each of those herds were selected. Herds were enrolled on the basis of undertaking routine production recording; recording cow calving, breeding, and disease data in an electronic format; and undertaking whole-herd dated pregnancy diagnosis.

Animal records including calving date, disease, and milk production data were downloaded from a central electronic database (LIC, Newstead, New Zealand) before the start of the seasonal calving period. Data were transferred into a purpose-built database (Access, Microsoft Corp., Redmond, WA), and a random sample of 40 cows was selected from each herd for examination at one time point, approximately $30 \mathrm{~d}$ before the start of the herds' seasonal breeding program. Cows were excluded if they had not calved at the time of scheduled examination, if ill, or if they had been treated with 
antimicrobials in the $14 \mathrm{~d}$ preceding the scheduled examination. Cows were also excluded if the herd owner intended to cull the cow before the end of lactation or withhold the cow from breeding. Calved cows were examined using a Metricheck device (Simcro) and scored on a 0 to 5 scale (McDougall et al., 2007), where 0 indicated that no material was recovered from the vagina. For analysis, scores 0 and 1 were combined and presented as 1 . The BCS was determined (1 to 10 scale; Roche et al., 2004) and samples were collected for cytology using a double-guarded mare uterine swab within which a cytobrush mounted on a metal stylet was placed (Kasimanickam et al., 2004b; Barlund et al., 2008).

Following commencement of the breeding program (planned start of mating; PSM), cows were bred by AI upon detection of estrus for an average of $46 \mathrm{~d}$ (range: 20 to $85 \mathrm{~d}$ ), followed by introduction of service bulls until a mean of $77 \mathrm{~d}$ (range: 57 to $110 \mathrm{~d}$ ) after the PSM. Pregnancy diagnosis was undertaken using transrectal ultrasonography and occurred at a mean of $83 \mathrm{~d}$ (range: 73 to $126 \mathrm{~d}$ ) after the PSM. Date of conception was estimated by subtracting the estimated stage of gestation from the date of the pregnancy diagnosis.

\section{Power Analysis}

The study was designed to have sufficient power to obtain a cow-level estimate of endometritis of $\pm 5 \%$. The Se and Sp of cytology for diagnosing endometritis were assumed to be 75 and $85 \%$, respectively (M. W. de Boer, AlcheraBio, New Brunswick, NJ, personal communication), the within-herd prevalence of endometritis was expected to be $8 \%$, and the within-herd clustering was assumed to be 0.1. Adjusting for test Se and Sp (Thrusfield, 2007) and for clustering within herd (Dohoo et al., 2003), a sample size of 2,000 cows, consisting of 20 cows from each of 100 herds, was required. For an individual herd using a sample size of 20 animals per herd and using the same assumptions around true prevalence, test Se and Sp and assuming $95 \%$ confidence, the precision was $\pm 31 \%$ (Humphry et al., 2004).

\section{Laboratory Procedures}

The cytology slides were air-dried after smearing of the endometrial sample, and then stained using a modified Romanowsky stain (Diff-Quik, Amber Scientific Ltd., Midvale, Western Australia, Australia). Following addition of a coverslip, each slide was assessed by a trained veterinary pathologist using light microscopy to calculate the proportion of PMN cells among a population of $>200$ nucleated cells per slide. The repeatability of the counting process had been previously validated in the laboratory using the same process and pathologist (D. Aberdein) who undertook the assessment of the slides in the current study (McDougall et al., 2011).

\section{Data Analysis}

Analyses were undertaken using STATA (version 16.0; STATACorp LLC, College Station, TX) and Winbugs version 1.4 (https://www.mrc-bsu.cam.ac.uk/ software/bugs/the-bugs-project-winbugs/). The primary outcome variables were PMN\% and PVD score, and secondary outcomes included the 3 -wk submission rate, conception rate to first $\mathrm{AI}$, and proportion of cows pregnant by 3 and 6 wk after the start of the seasonal breeding program.

The PMN\% cut-point to define endometritis was assessed using a receiver operator characteristic (ROC) curve analysis with failure to conceive to first service as the outcome variable, and PMN\% (categorized into percentages up to 10\%) as the independent variable. A nonparametric model was used initially, where Se and Sp for each cut-point were calculated (ROCTAB; Pepe et al., 2009). The effect of DIM at sampling on the ROC was assessed by including DIM at enrollment in the ROC models as either a categorical or a continuous variable, as well as repeating ROC analysis for cows calved $<4 \mathrm{wk}, 4$ to $6 \mathrm{wk}$, and $>6 \mathrm{wk}$ at enrollment. Models that did, or did not, account for DIM at enrollment were compared graphically and statistically (ROCOMP). Finally, modeling adjusting for clustering of cows within herd was undertaken, both with and without DIM at enrollment as a covariate (ROCREG). The sum of Se and Sp for PVD scores $\geq 2$ and $\geq 3$ were similar. Hence, for estimates of herd-level prevalence, a score of $\geq 2$ was used to align with commonly used clinical threshold for treatment in New Zealand (McDougall et al., 2011). However, when multivariable modeling including both PMN\% and PVD score was undertaken, model fit was better where a score of $\geq 3$ was used (see Effect of Simultaneous Assessment of PMN\% and PVD Score on Reproductive Performance).

The selected cut-points (PMN\% $\geq 2 \%$, PVD score $\geq 2$ ) were then used to define the within-herd and population prevalences of endometritis. Because 2-stage sampling was undertaken and the probability that any one animal within any one herd being selected was not equal, a weighted probability of selection was included in the prevalence estimates.

To assess the degree of clustering of the PMN\% or PVD score of cows within herd, the intraclass correlation (ICC or rho) was calculated using a null multilevel model, with herd as the group (or cluster) and animals within herd as the observations. 
Associations between cows with a low $(<2 \%)$ or elevated $(\geq 2 \%)$ PMN\% and reproductive outcomes were assessed using bivariate (chi-squared) analyses. Associations between PVD score (categorized as 1, 2, 3, >3) and reproductive outcomes were assessed initially using bivariate (chi-squared) analyses. Binary logistic regression analysis was then undertaken with PVD score as the main effect. Pairwise multiple comparisons among scores were undertaken using the "pwcompare" statement in STATA. Attempts to model the PVD outcomes using random effects models failed due to presence of null cells. To assess whether PMN\% and PVD score were additive or independent, multivariable logistic regression models were run for the key reproductive outcome variables, with $\mathrm{PMN} \%$ (categorized $\leq 2 \%$ vs. $>2 \%$ ), and PVD score (categorized as $1+2$ versus $\geq 3$ ) as independent variables. The models were initially run with these main effects and the first-order interaction; then, if the interaction was not significant (i.e., $P>$ $0.05)$, the models were rerun with the 2 predictor variables as main effects. From these models, the estimated marginal means and 95\% confidence intervals were calculated. The level of agreement between the PMN\% score (categorized as $\leq 2 \%$ vs. $>2 \%$ ) and PVD scores (coded either as 1 vs. $\geq 2$ or $1+2$ vs. $\geq 3$ ) were assessed using the kappa statistic.

Latent class modeling was used to assess the Se and Sp of cytology and PVD score at the cut-points selected using ROC analyses and to calculate herd prevalence. The 2 tests were assumed to be nonindependent. The prevalence distribution was estimated using a previously published methodology (Branscum et al., 2004). Priors for the Se and Sp for PVD and cytology testing were based on a recently published study of Canadian cattle (Arango-Sabogal et al., 2019). The Se were defined a priori as 0.65 and 0.45 for PVD and cytology, respectively, and the Sp were defined as 0.97 and 0.92 , respectively. All parameters were constrained such that we were $95 \%$ sure that the Se and Sp were $>0.1$. The $\beta$ distributions were calculated using a publicly available distribution calculator (Betabuster, http://www .freedownload64.com/details/148262/betabuster.html). The prevalence was a priori assumed to be 0.2 . These data were then processed within a Bayesian LCM using a Markov chain Monte Carlo (MCMC) approach. The first 10,000 iterations were discarded ("burn in") and the Se, Sp, positive predictive value, negative predictive value, and within-herd prevalence were calculated using the next 50,000 iterations. Convergence was visually assessed on dynamic trace graphs and the deviance information criterion calculated. To assess the Se of the model to the assumed priors, models were run with noninformative priors [i.e., $\beta(1,1)]$, as well as the priors outlined above.

\section{RESULTS}

\section{Herds and Cows}

The average herd size was 598 cows (range 133 to 1,867; Table 1). Average herd milk yield was 23.7 (range 14.4 to 30.7$) \mathrm{kg} /$ cow per day at the first DHIA recording, which occurred at a median of 52 (range 14 to 126) DIM. A total of 1,806 cows were enrolled from the 100 herds. The herds were visited when cows were at an average of 40.6 (range 1 to 97) DIM and at an average of 29.5 (range 16 to 50) d before the PSM (Table 1).

For the sampled cows, conception rate to first AI was $52.1 \%$ (95\% CI: 49.8 to $54.4 \%$ ), the proportion bred in the first 3 wk of the seasonal breeding program was $88.1 \%$ (95\% CI: 86.5 to $89.5 \%)$, the proportion pregnant in the first 3 wk was $52.3 \%$ (95\% CI: 50.0 to

Table 1. The median and interquartile range (25th and 75th percentile) of herd size, milk production data, DIM at examination, cow age, BCS, and length of the breeding program for enrolled herds $(\mathrm{n}=100)$

\begin{tabular}{|c|c|c|c|c|c|c|c|}
\hline Item & \multicolumn{3}{|c|}{ Percentile } & Average & SE & \multicolumn{2}{|c|}{ Range } \\
\hline Herd size & 304 & 506 & 791 & 597.3 & 35.7 & 133 & 1,867 \\
\hline Milk fat $\%$ & 4.4 & 4.6 & 4.8 & 4.7 & 0.1 & 3.78 & 6.34 \\
\hline Protein \% & 3.7 & 3.8 & 3.9 & 3.8 & 0.0 & 3.20 & 4.22 \\
\hline Milk solids (kg/cow per day) & 1.8 & 2 & 2.2 & 2.0 & 0.0 & 1.29 & 2.63 \\
\hline Visit to $\operatorname{PSM}^{1}(\mathrm{~d})$ & 28 & 30 & 31 & 29.4 & 0.1 & 16 & 50 \\
\hline Length of AI period (d) & 31 & 40 & 66 & 46.8 & 2.0 & 20 & 85 \\
\hline Total breeding period length (d) & 69 & 77 & 82 & 77.2 & 1.0 & 57 & 110 \\
\hline Cow age $(\mathrm{yr})$ & 2.8 & 3.8 & 5.9 & 4.5 & 0.06 & 2 & 17 \\
\hline $\mathrm{BCS}^{2}$ & 4 & 4 & 4.5 & 4.2 & 0.01 & 3 & 7 \\
\hline
\end{tabular}

${ }^{1}$ Planned start of mating for the seasonal breeding program.

${ }^{2}$ On a scale of 1 to 10 (Roche et al., 2004). 


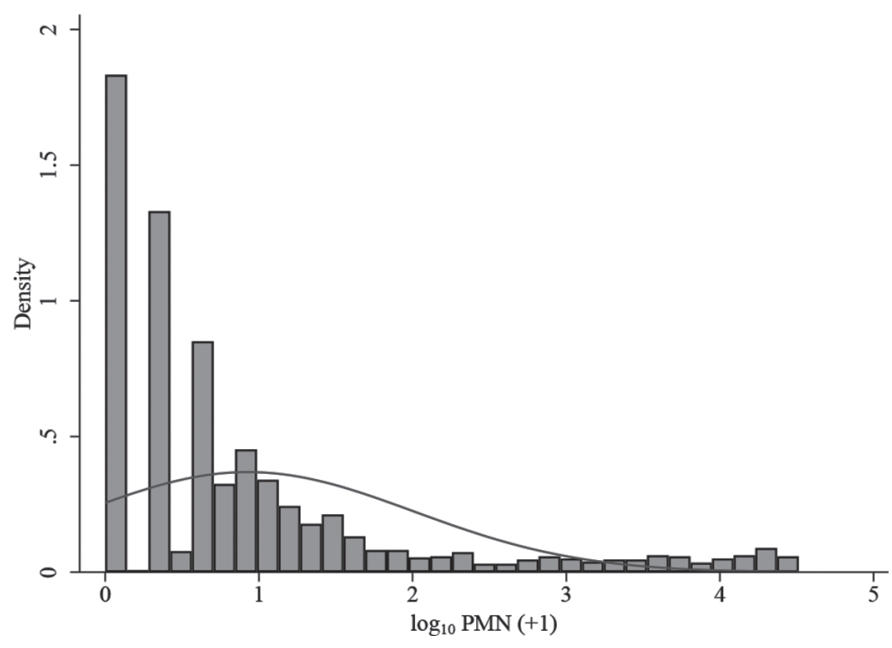

Figure 1. Frequency histogram of the $\log _{10}(\mathrm{PMN}+1)$ from 1,806 cows (from 100 herds) sampled on average at $42 \mathrm{~d}$ postpartum. A normal distribution curve is overlaid.

$54.6 \%$ ), and the proportion pregnant in the first $6 \mathrm{wk}$ was $74.1 \%$ (95\% CI: 72.1 to $76.1 \%$ ).

\section{PMN Distribution and ICC}

The average herd PMN\% was 5.5\% (range 0.5 to 19.4\%). The PMN\% was not normally distributed skewness $=3.8$, kurtosis $=17.1$ ) and hence was $\log _{10}$ transformed after the addition of 1 (due to presence of $0 \%$ values; Figure 1). The ICC (rho) was 0.03 (chisquared $P=0.025)$.

\section{PMN Cut-Point}

The PMN\% was weakly associated with conception at first AI (area under the curve $=0.53 ; 95 \%$ CI: 0.51

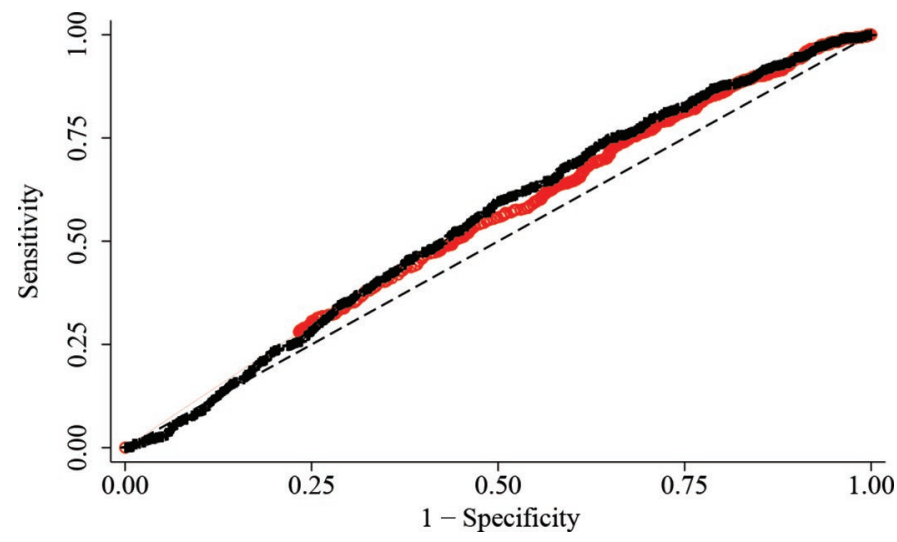

Figure 2. The sensitivity and 1 - specificity (i.e., receiver operator characteristic curves) for PMN \% as a predictor of failure to conceive with (blue line) or without (red line) DIM at enrollment as a covariate. The diagonal dashed line represents the reference (or chance) line.

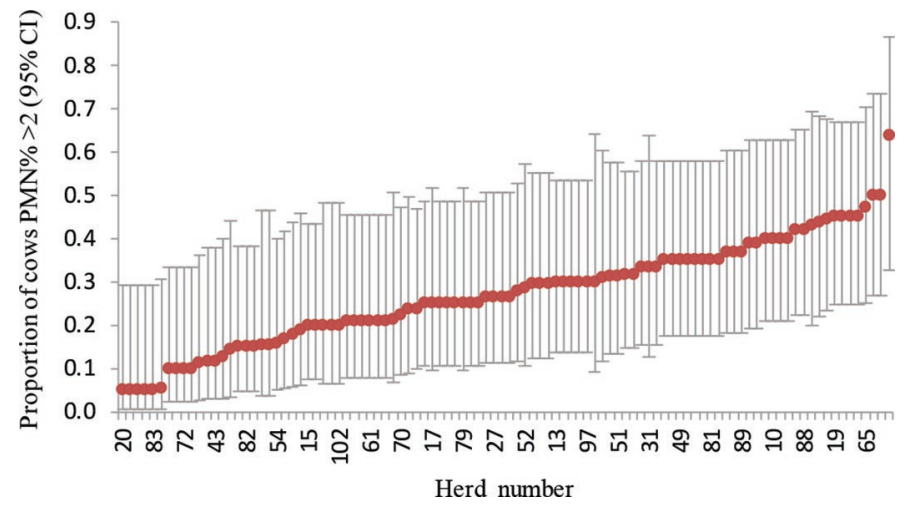

Figure 3. Proportion of cows (95\% CI) by herd (x-axis) with percentage neutrophils (PMN) $\geq 2 \%$ from 1,806 cows (from 100 herds) sampled on average at $42 \mathrm{~d}$ postpartum.

to 0.56 ; Figure 2). The maximum Youden index (i.e., sum of Se and Sp) occurred at a cut-point of $\geq 2 \%$ PMN (Table 2).

Days in milk was not significant $(P>0.1)$ and resulted in a $<1 \%$ change in the area under the curve (0.546 vs. 0.552 for models without and with DIM at enrollment as a covariate, respectively; Figure 2). However, the optimal cut-point (maximum of sum of Se and Sp) occurred at PMN $\%$ cut-points of $\geq 6 \%, \geq 2 \%$, and $\geq 3 \%$, where cows had been calved $<4$ wk, 4 to $6 \mathrm{wk}$, or $>6$ wk, respectively.

\section{Prevalence of Elevated PMN\%}

A total of $27.0 \%$ (95\% CI: 25.0 to $29.1 \%$ ) of the cow population had a PMN $\% \geq 2$. The herd mean prevalence of PMN $\% \geq 2$ was $27.1 \%$ (95\% CI: $24.7 \%$ to $29.6 \%$ ), and prevalence varied among herds $(P<0.001$; Figure 3$)$.

Table 2. Sensitivity (Se), specificity (Sp), correct classification, and Youden index (i.e., the sum of the Se and $\mathrm{Sp}$ ) at a given percentage neutrophils (PMN\%) cut-point when classifying the likelihood of cows not conceiving to first $\mathrm{AI}$

\begin{tabular}{lrrcc}
\hline $\begin{array}{l}\text { PMN } \\
\text { cut-point }\end{array}$ & $\begin{array}{c}\text { Se } \\
(\%)\end{array}$ & $\begin{array}{c}\text { Sp } \\
(\%)\end{array}$ & $\begin{array}{c}\text { Correctly } \\
\text { classified (\%) }\end{array}$ & $\begin{array}{c}\text { Youden } \\
\text { index (\%) }\end{array}$ \\
\hline$\geq 0$ & 100.0 & 0.0 & 47.8 & 100.0 \\
$\geq 1$ & 44.3 & 60.1 & 52.5 & 104.4 \\
$\geq 2$ & 30.1 & 76.8 & 54.5 & 106.8 \\
$\geq 3$ & 23.6 & 82.2 & 54.2 & 105.7 \\
$\geq 4$ & 19.8 & 86.3 & 54.5 & 106.1 \\
$\geq 5$ & 18.1 & 88.1 & 54.6 & 106.2 \\
$\geq 6$ & 16.7 & 89.2 & 54.5 & 105.8 \\
$\geq 7$ & 15.5 & 90.0 & 54.4 & 105.5 \\
$\geq 8$ & 14.4 & 90.0 & 53.9 & 104.4 \\
$\geq 9$ & 13.7 & 90.8 & 53.9 & 104.5 \\
$\geq 10$ & 12.6 & 91.2 & 53.6 & 103.7 \\
\hline
\end{tabular}


Table 3. Bivariate associations between cows with a low $(<2 \%)$ or elevated $(\geq 2 \%)$ percentage neutrophils (PMN\%) when examined approximately $42 \mathrm{~d}$ after calving, and the proportion of cows conceiving to first AI, the proportion inseminated in the first 3 wk of the breeding program, and the proportion confirmed pregnant by 3 and 6 wk of the seasonal breeding program

\begin{tabular}{|c|c|c|c|c|c|c|}
\hline Item & PMN\% & No & Yes & Total & $\%$ & $P$-value ${ }^{1}$ \\
\hline \multirow[t]{2}{*}{ Conception to first AI } & $<2$ & 579 & 694 & 1,273 & 54.5 & $<0.001$ \\
\hline & $\geq 2$ & 249 & 210 & 459 & 45.8 & \\
\hline \multirow[t]{2}{*}{$\mathrm{AI}$ in $3 \mathrm{wk}$} & $\overline{<} 2$ & 142 & 1,179 & 1,321 & 89.3 & $<0.001$ \\
\hline & $\geq 2$ & 79 & 405 & 484 & 83.7 & \\
\hline \multirow[t]{2}{*}{ Pregnant in $3 \mathrm{wk}$} & $\overline{<} 2$ & 568 & 705 & 1,273 & 55.4 & $<0.001$ \\
\hline & $\geq 2$ & 255 & 204 & 459 & 44.4 & \\
\hline \multirow[t]{2}{*}{ Pregnant in $6 \mathrm{wk}$} & $\overline{<2}$ & 301 & 972 & 1,273 & 76.4 & $<0.001$ \\
\hline & $\geq 2$ & 149 & 310 & 459 & 67.5 & \\
\hline
\end{tabular}

${ }^{1}$ Derived from chi-squared analyses.

\section{Association Between Elevated PMN\% and Reproductive Performance}

Compared with cows with a low $(<2)$ PMN\%, an elevated $(\geq 2)$ PMN\% was associated with a reduction in the proportion of cows conceiving to the first AI [45.8\% (95\% CI: 41.2 to $50.3 \%)$ vs. $54.5 \%$ (95\% CI: 51.8 to $57.3 \%) ; P<0.001$ ], a reduced proportion of cows detected in estrus and bred in the first $3 \mathrm{wk}$ of the breeding program [83.7\% (95\% CI: 80.1 to $87.3 \%$ ) vs. $89.3 \%$ (95\% CI: 87.3 to $91.2 \%$ ); $P<0.001$ ], a lower proportion pregnant in the first $3 \mathrm{wk}[44.4 \%$ (95\% CI: 39.9 to $49.0 \%$ ) vs. $55.4 \%$ (95\% CI: 52.6 to $58.1 \%$ ); $P$ $<0.001$ ], and a lower proportion of cows pregnant in the first 6 wk of the breeding program $[67.5 \%(95 \% \mathrm{CI}$ : 63.3 to $72.2 \%$ ) vs. $76.4 \%$ (95\% CI: 73.6 to $78.8 \%$ ); $P<$ 0.001; Table 3].

\section{PVD Score}

The PVD scores across the study population were $75.4,17.6,4.0,2.5$, and $0.6 \%$ for scores $1,2,3,4$ and 5 , respectively. The ICC (rho) was 0.05 (chi-squared $P$ $<0.001$ ). The herd-average prevalence of PVD score $\geq 2$ was $25.1 \%$ (95\% CI: 22.5 to $27.7 \%$ ), and prevalence varied among herds $(P<0.001 ;$ Figure 4$)$.

\section{Associations Among PVD Score, Reproductive Performance, and PMN\%}

The PVD score was negatively associated with the proportion of cows conceiving to the first AI and the proportion pregnant in the first 3 and 6 wh of the breeding program (Table 4).

The level of agreement (kappa) between PVD score (categorized as 1 vs. $\geq 2)$ and PMN\% $(<2$ vs. $\geq 2)$ was low $(16.8 \%)$ and not significant $(P=1.0$; Table 5$)$. Similarly, if the comparison was made using a higher PVD cut-point (i.e., $1+2$ vs. $>2$ ), there was still no significant level of agreement (Table 5).

\section{Effect of Simultaneous Assessment of PMN\% and PVD Score on Reproductive Performance}

Where both PMN\% and PVD score were included as explanatory variables in the same model, a PMN\% of $\geq 2$ was associated with reduced conception to first AI, reduced likelihood of $\mathrm{AI}$ in the first $3 \mathrm{wk}$, and reduced

Table 4. Purulent vaginal discharge (PVD) score for cows examined approximately $42 \mathrm{~d}$ after calving, the proportion of cows within each PVD category that had elevated percentage neutrophils (PMN\%; i.e., $\geq 2 \%$ ), and conception to first AI, proportion AI in the first $3 \mathrm{wk}$ of the seasonal breeding program, and pregnant in 3 and 6 wk of the seasonal breeding program

\begin{tabular}{lccccc}
\hline & \multicolumn{5}{c}{ PVD score } \\
\cline { 2 - 5 } Item & 1 & 2 & 3 & $>3$ & $P_{\text {-value }}$ \\
\hline Cows, no. & 1,361 & 317 & 72 & 56 & \\
Cows, \% & 75.4 & 17.6 & 4.0 & 3.1 & \\
Cows with $\geq 2 \%$ PMN, $\%$ & 22.3 & 33.8 & 54.2 & 67.9 & \\
Conception to first AI & $52.9^{\mathrm{a}}$ & $54.6^{\mathrm{a}}$ & $47.9^{\mathrm{ab}}$ & $31.5^{\mathrm{b}}$ & 0.01 \\
AI in 3 wk & 87.8 & 86.9 & 90.5 & 80.0 & 0.30 \\
Pregnant in 3 wk & $53.3^{\mathrm{a}}$ & $53.3^{\mathrm{a}}$ & $46.6^{\mathrm{ab}}$ & $35.2^{\mathrm{b}}$ & 0.05 \\
Pregnant in 6 wk & $75.6^{\mathrm{a}}$ & $74.2^{\mathrm{a}}$ & $68.5^{\mathrm{a}}$ & $50.0^{\mathrm{b}}$ & 0.00 \\
\hline
\end{tabular}

$\overline{\mathrm{a}, \mathrm{b}}$ Values with different superscripts within a row differ at $P<0.05$.

${ }^{1} P$-value is the chi-squared (bivariate) value. 


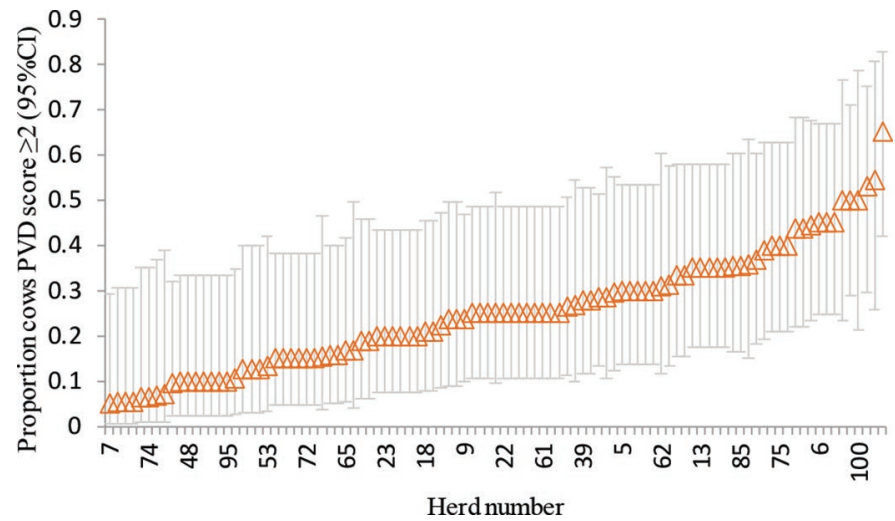

Figure 4. Proportion of cows (95\% CI) by herd (x-axis) with a positive purulent vaginal discharge (PVD) score $(\geq 2)$ from 1,747 cows (from 100 herds) sampled on average at $42 \mathrm{~d}$ postpartum.

pregnancy at 3 and 6 wk (Table 6 ). A PVD score $\geq 3$ tended to be associated with a lower conception to first $\mathrm{AI}$ and a lower pregnancy proportion by $6 \mathrm{wk}$ (Table $6)$. In no case was there an interaction of PMN\% and PVD score $(P>0.5)$.

\section{Sensitivity and Specificity Estimates from Bayesian LCM}

The Se and Sp were higher for PVD than for cytology (Table 7). There was no substantive difference in the estimates of Se, Sp, positive predictive value, negative predictive value, or within-herd prevalence between the models using noninformative compared with informative priors. However, the average within-herd prevalence estimate was numerically higher from the model with noninformative priors than from that using more informative priors (Figure 5; Table 7).

\section{DISCUSSION}

This study provided an estimate of cow- and herdlevel prevalence of endometritis in pasture-based, seasonal-calving dairy herds. This was achieved using 1,806 cows in 100 herds in New Zealand and implementing frequentist and Bayesian LCM analytical approaches. Our estimate that at least $20 \%$ of cows have endometritis approximately $4 \mathrm{wk}$ before the onset of a

Table 5. The number of cows within categories of purulent vaginal discharge score (PVD; coded as 1 vs. $\geq 2$ or as $1+2$ vs. $\geq 3$ ) and percentage neutrophils (PMN\%; coded as $<2 \%$ and $\geq 2 \%$ )

\begin{tabular}{lrlrrrr}
\hline & \multicolumn{2}{c}{ PVD score } & & \multicolumn{2}{c}{ PVD score } & Total \\
\cline { 2 - 3 } \cline { 6 - 7 } PMN\% & \multicolumn{1}{c}{1} & $\geq 2$ & & $1+2$ & $\geq 3$ & \\
\hline$<2$ & 1,058 & 261 & & 1,268 & 51 & 1,319 \\
$\geq 2$ & 303 & 184 & & 410 & 77 & 487 \\
\hline
\end{tabular}

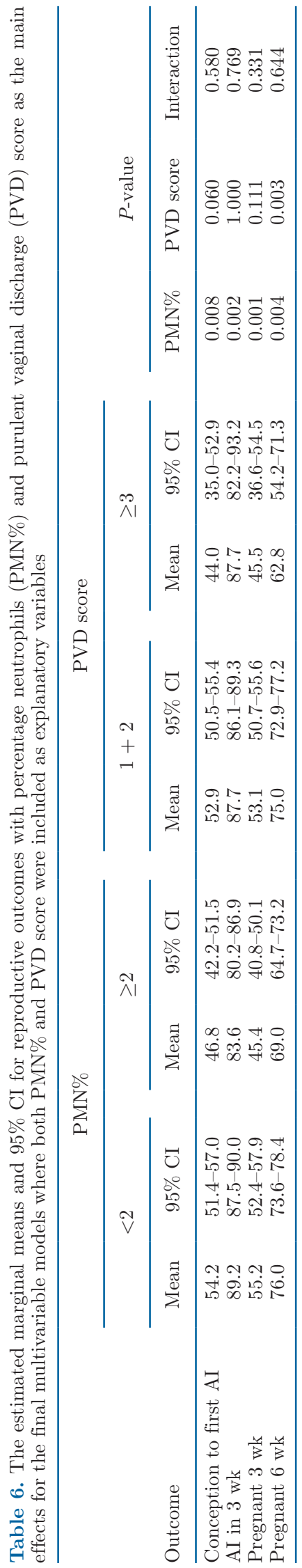


seasonal breeding program and the fact that this condition reduces reproductive performance support the rationale for devising solutions to lessen the risk for persistent endometritis at both the cow and herd levels.

The terminology used for endometritis in cattle varies widely among researchers. We have chosen to use the word "endometritis" to indicate inflammation of the endometrium, irrespective of the diagnostic method used to define it. Hence, we have differentiated between diagnoses reached following use of cytology from diagnoses following use of vaginal discharge score.

By design, the current study sampled cows within herds. This hierarchical or cluster design was used to try to estimate the prevalence and variance of endometritis both at the herd and cow levels. Where clustering exists within a study, such clustering should be accounted for by the design of the statistical models (Dohoo et al., 2003). An understanding of where the largest unexplained variation sits, at either the herd or cow level,

(a)

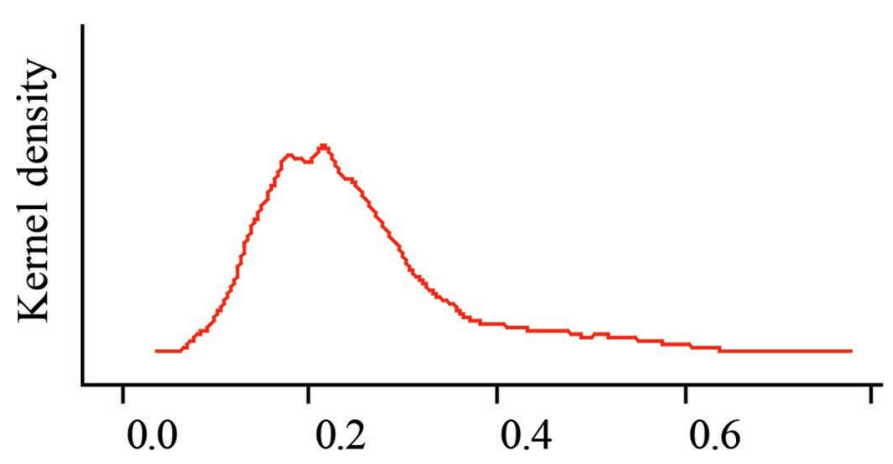

(b)

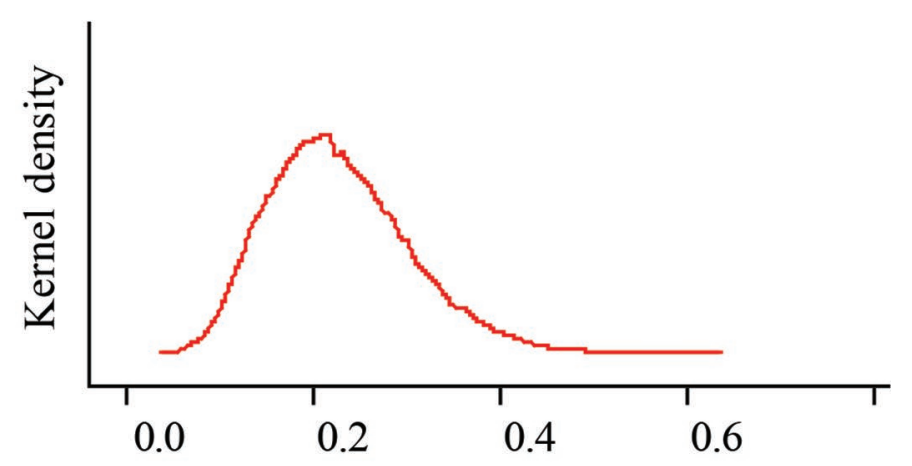

Prevalence

Figure 5. Kernel density (y-axis) plots of within-herd prevalence (x-axis) of endometritis from 1,747 cows (from 100 herds) sampled on average at $42 \mathrm{~d}$ postpartum from latent class models in which both purulent vaginal discharge (PVD) and percentage neutrophils (PMN\%) were included as explanatory variables and where the priors were (a) noninformative, or (b) informative.
Table 7. The mean and Bayesian 95\% confidence interval (95\% BCI) for the sensitivity (Se), specificity (Sp), positive predictive value $(\mathrm{PPV})$, negative predictive value (NPV), and within-herd prevalence for latent class models with noninformative or informative priors (final model) for diagnosis of endometritis following examination for presence of purulent vaginal discharge (PVD) and uterine cytology

\begin{tabular}{lrrrrr}
\hline & \multicolumn{2}{c}{ Noninformative model } & & \multicolumn{2}{c}{ Final model } \\
\cline { 2 - 3 } \cline { 5 - 6 } Trait & Mean & $(95 \%$ BCI $)$ & & Mean & $(95 \%$ BCI $)$ \\
\hline PVD & & & & & \\
Se & 71.1 & $(35.9-97.5)$ & & 70.7 & $(46.8-93.4)$ \\
Sp & 89.5 & $(81.6-98.5)$ & & 88.1 & $(81.2-95.4)$ \\
PPV & 67.5 & $(35.3-96.1)$ & & 62.2 & $(33.1-87.7)$ \\
NPV & 88.3 & $(53.7-99.5)$ & & 90.2 & $(72.9-98.8)$ \\
Cytology & & & & & \\
Se & 32.5 & $(11.1-53.0)$ & & 33.8 & $(16.1-52.7)$ \\
Sp & 74.9 & $(68.2-83.4)$ & & 75.0 & $(69.5-81.5)$ \\
PPV & 30.8 & $(6.0-64.6)$ & & 28.4 & $(9.5-54.4)$ \\
NPV & 76.4 & $(44.4-90.7)$ & & 79.2 & $(61.7-91.5)$ \\
Prevalence & 25.6 & $(10.8-54.8)$ & & 22.9 & $(10.4-40.1)$ \\
DIC & $1,101.0$ & & & $1,100.0$ & \\
\hline
\end{tabular}

${ }^{1}$ Deviance information criterion.

provides guidance as to where interventions should be aimed. For example, if there is large unexplained variation between herds in endometritis prevalence, it would indicate that if factors could be identified to explain this variation, these could be exploited by appropriate interventions at the herd level. Conversely, if most of the variance resides at the cow level, then cow-level interventions are likely to have the most utility (Dohoo et al., 2003). The degree of clustering (the ICC or rho) was 3 and $5 \%$ for PMN\% and PVD score, respectively, in the current study. Because the ICC was significant in both cases, models accounting for the clustered nature of the data (i.e., cow within herd) were required to ensure the correct variance was calculated. However, these ICC are low relative to ICC commonly reported for disease or production measures (Dohoo et al., 2003). This suggests that although disease statuses of cows within a given herd are more closely correlated than those of cows from another herd, most of the variation is at the cow, rather than herd, level in this study. Practically, this suggests that interventions to reduce prevalence or incidence of endometritis should involve diagnosis or treatment of cows on an individual basis, rather than focusing on whole-herd interventions.

Exclusion of ill cows or those that had been treated with antimicrobials in the $14 \mathrm{~d}$ before the planned visit was done for operational reasons, because treated animals are managed as a separate group from healthy cows and hence are less accessible. This may have led to an underestimate of true prevalence where cows with endometritis or PVD were amongst the population of ill or recently treated animals. Additionally, the use of convenience sampling of herds may have introduced some bias. The requirement for good on-farm records as 
well as herd owner cooperation were factors contributing to the use of a convenience rather than a random sample of herds. Whether herd owners who maintained good records and had a willingness to collaborate with researchers also managed animals in such a way as to reduce or increase the prevalence of endometritis is unknown. Despite enrollment of nearly 1,800 cows and 100 herds, there was a lack of precision in estimates of endometritis prevalence within each herd. The initial power calculations assumed that true prevalence would be approximately $8 \%$. In reality, prevalence was $>20 \%$, with resultant loss of precision, because the effect of increasing prevalence is to increase the sample size to achieve a given precision. Additionally, the precision of the estimate of prevalence within any one herd was approximately $\pm 30 \%$. During study design, varying sample sizes within herd and numbers of herds were modeled to optimize the precision of estimates at the cow and within-herd levels but also to minimize costs of conducting the study. Increasing the number of animals sampled within each herd would have increased the precision of the estimate of endometritis prevalence in that herd but reduced the number of herds that could have been sampled.

The cut-point of PMN\% that resulted in the highest Se and $\mathrm{Sp}$ (i.e., the highest Youden index) was $\geq 2 \%$. This cut-point is lower than has been used in previous studies, which have ranged from 4 to $18 \%$, depending on the DIM when examination occurred (reviewed by de Boer et al., 2014). As has been previously reported, the optimal cut-point declines with DIM. The reported optimal cut-points were $\geq 6 \%$ and $\geq 4 \%$ when cows were examined at 35 and 56 DIM, respectively (Dubuc et al., 2010). The lower optimal cut-point reported in the current study is partly a result of examination occurring at greater DIM than for some other studies (i.e., at an average of 41 DIM in the current study), but potentially also as a result of a truly lower prevalence of intrauterine inflammation in the New Zealand dairy cow population than in other cattle populations, and a different outcome variable against which the ROC analysis was undertaken. Previously reported studies have optimized the ROC against the proportion of cows pregnant by some defined number of DIM. In seasonal breeding programs, such an outcome variable is potentially confounded for ROC analysis. This is because there is no voluntary waiting period; rather, a calendar day is selected when the breeding program commences. Thus, a cow calving early in the calving period has a long interval before the start of breeding and is precluded from conceiving until the calendar date on which the breeding program commences. Conversely, a cow calving late in the calving period has a reduced interval to the start of the breeding program and is eligible for breeding at fewer DIM than an earlier calving cow. For this reason, the PMN\% cut-point was optimized against the likelihood of conception to first AI, not the proportion of cows pregnant by some DIM.

The cow and herd prevalences of cows with $\geq 2 \%$ PMN (cytological endometritis) were 27.0 and $27.1 \%$, respectively, with substantial variation among herds. Further studies are required to define the herd-level factors associated with this variation in the prevalence of endometritis diagnosed by cytology. It is not clear whether the variation in prevalence can be explained simply by variation among herds in the prevalence of cow-level risk factors, or whether herd-level decisions such as genetics, nutrition, or herd policy around calving assistance and various other managerial interventions may account for the observed variation.

A meta-analysis (de Boer et al., 2014) found that the majority of tests for endometritis were not well validated, with issues associated with descriptions of methodology, definitions of population of animals, and lack of details around test performance. For cytology, several studies have reported intra- and interobserver agreement, with intraobserver agreement varying from 0.76 to 0.82 , and interobserver agreement varying from 0.77 to 0.90 (de Boer et al., 2014). The PMN\% is calculated by counting a minimum of 100 (Kasimanickam et al., 2004b; Barlund et al., 2008; Dubuc et al., 2010; McDougall et al., 2011) or 200 (Madoz et al., 2013) nucleated cells. One issue that appears not to have been addressed is the precision of such counts. Increasing the number of nucleated cells assessed increases the precision. For example, exact binomial confidence intervals can be calculated, and this approach demonstrates that if a cut-point of $2 \%$ PMN were used and 100 nucleated cells counted, then the width of the $95 \%$ CI is $6.8 \%$ (i.e., 0.2 to $7.0 \%$ ). Increasing the sample size to 200 cells reduces the width of the $95 \%$ CI to $4.5 \%$ (i.e., 0.5 to $5.0 \%$ ). As the cut-point increases, the precision of the estimate declines. So, for example, if a $5 \%$ cut-point is used and 200 nucleated cells are counted, then the $95 \%$ CI width is $6.6 \%$ (i.e., 2.4 to $9.0 \%$ ). The current study counted 200 nucleated cells and the cut-point used was $2 \%$ (i.e., $4 \mathrm{PMN}$ ), so the $95 \%$ CI was 0.5 to $5 \%$. Some of the between-herd variation in apparent prevalence will be associated with the lack of precision of the estimated PMN\%.

The prevalence of PVD (as assessed using a PVD score of $\geq 2$ ) was 24.6 and $25.1 \%$ at the cow and herd levels, respectively. This is higher than previously reported $(21 \%)$ for pasture-based cattle (McDougall et al., 2007); the reason for this higher prevalence is unknown. One difference between the current and the previous study was the inclusion of a wider geographic spread of herds in the current study. Regional differ- 
ences in management practices may account for the observed difference.

Assessing the presence of purulent material in the vagina is quick, easy to undertake, and cheap to implement and hence is widely used clinically. However, although PVD score is associated with endometritis, it is not synonymous with endometritis (McDougall et al., 2007; Dubuc et al., 2010). The association between PMN\% and PVD score in the current study was relatively weak (kappa $=0.17)$. In seasonal breeding systems, agreement (kappa) has been reported to be 0.12 to 0.29 , depending on the DIM at examination and the PMN\% cut-point used (McDougall et al., 2011). Similar estimates were reported from cows calving year-round in Canada (Dubuc et al., 2010). The implication is that the 2 tests are measuring different things. This is reinforced by the finding in the current study that, even though both PMN\% and PVD score were associated with reproductive outcomes, there was no interaction between the 2 measurements. As well as being quick and cheap to obtain, the PVD score can be the basis for interventions that improve reproductive outcomes (Runciman et al., 2008). Therefore, while PMN\% is associated with reproductive outcomes, and intervention studies have demonstrated a positive effect of treating PMN positive cows (Denis-Robichaud and Dubuc, 2015b), the invasive nature of the test, the time required, and the need for laboratory processes to reach a diagnosis preclude its widespread application.

There is no gold standard for endometritis diagnosis. In the absence of a gold standard, Bayesian LCM are commonly used to provide estimates of Se and Sp (Branscum et al., 2004, 2005). A recent multi-herd Canadian study provided the first Bayesian LCM estimates for Se and Sp for leukocyte esterase, cytology, and PVD score for endometritis in cattle (Arango-Sabogal et al., 2019). The current study demonstrated that the Se and Sp were higher for PVD than for cytology. In agreement with the Canadian study and a previous New Zealand study (McDougall et al., 2007), we found that the optimal cut-point for PVD score was $\geq 2$, which is lower than has been reported for other studies where a cut-point of $\geq 3$ has been used (Runciman et al., 2009; Dubuc et al., 2010). As may be expected when a higher cut-point is used, the Se of PVD was lower and the Sp higher. In the current study, where reproductive performance was assessed against PVD score, animals with a PVD score of 2 did not have poorer reproductive performance than those with a score of 1 . However, the Bayesian LCM suggested that a cut-point $\geq 2$ was optimal. The reason for this apparent paradox may be that the initial analysis used reproductive outcomes as the gold standard. Thus, the test cut-point was being optimized against an outcome variable that occurred a month or more after diagnosis. In contrast, the Bayesian analysis used the cytology test undertaken at the same time as a comparison point.

\section{CONCLUSIONS}

Endometritis, diagnosed either by cytology or PVD score, is prevalent in pasture-based, seasonal-calving herds, with $>20 \%$ of animals affected at an average of 41 DIM. There is large variation among herds in the prevalence of endometritis diagnosed by either method. Reasons for this variation are currently unknown and require further investigation. Diagnosis of endometritis by either method is associated with poorer reproductive outcomes.

\section{ACKNOWLEDGMENTS}

This study had complex and substantial logistical requirements. The technical assistance of DairyNZ technicians (Kate Watkins, Ben Fisher, Hamish Hodgson; Hamilton, New Zealand) as well as the Cognosco technicians (Cathy Yanez, Elizabeth Blythe, Joanne Niethammer, Erin Garnett, Cassandra Ryder, Tessa Hancock, Doug Maxwell, Tricia Rabarts, and Allan Findlay; Morrinsville, New Zealand) is gratefully acknowledged. The technical support of the Vetlife technicians is acknowledged (Temuka, New Zealand). Herd owners are gratefully acknowledged for allowing access to their herds. This project was funded by a partnership fund (DRCX1302) between the New Zealand Ministry of Business, Innovation and Employment and New Zealand dairy farmers through DairyNZ Inc. (RD1404). The authors have no conflicts of interest.

\section{REFERENCES}

Akhtar, S., I. A. Gardner, D. W. Hird, and J. C. Holmes. 1988. Computer simulation to compare three sampling plans for health and production surveillance in California dairy herds. Prev. Vet. Med. 6:171-181. https://doi.org/10.1016/0167-5877(88)90029-3.

Arango-Sabogal, J. C., J. Dubuc, C. Krug, J. Denis-Robichaud, and S. Dufour. 2019. Accuracy of leukocyte esterase test, endometrial cytology and vaginal discharge score for diagnosing postpartum reproductive tract health status in dairy cows at the moment of sampling, using a latent class model fit within a Bayesian framework. Prev. Vet. Med. 162:1-10. https://doi.org/10.1016/j.prevetmed .2018.11.003.

Barlund, C. S., T. D. Carruthers, C. L. Waldner, and C. W. Palmer. 2008. A comparison of diagnostic techniques for postpartum endometritis in dairy cattle. Theriogenology 69:714-723. https://doi .org/10.1016/j.theriogenology.2007.12.005.

Bicalho, M. L. S., F. S. Lima, V. S. Machado, E. B. Meira Jr., E. K. Ganda, C. Foditsch, R. C. Bicalho, and R. O. Gilbert. 2016. Associations among Trueperella pyogenes, endometritis diagnosis, and pregnancy outcomes in dairy cows. Theriogenology 85:267-274. https://doi.org/10.1016/j.theriogenology.2015.09.043.

Bogado Pascottini, O., M. Hostens, P. Dini, J. Vandepitte, R Ducatelle, and G. Opsomer. 2016. Comparison between cytology 
and histopathology to evaluate subclinical endometritis in dairy cows. Theriogenology 86:1550-1556. https://doi.org/10.1016/j .theriogenology.2016.05.014.

Branscum, A. J., I. A. Gardner, and W. O. Johnson. 2004. Bayesian modeling of animal- and herd-level prevalences. Prev. Vet. Med. 66:101-112. https://doi.org/10.1016/j.prevetmed.2004.09.009.

Branscum, A. J., I. A. Gardner, and W. O. Johnson. 2005. Estimation of diagnostic-test sensitivity and specificity through Bayesian modeling. Prev. Vet. Med. 68:145-163. https://doi.org/10.1016/j .prevetmed.2004.12.005.

Chapwanya, A., K. G. Meade, F. Narciandi, P. Stanley, J. F. Mee, M. L. Doherty, J. J. Callanan, and C. O'Farrelly. 2010. Endometrial biopsy: A valuable clinical and research tool in bovine reproduction. Theriogenology 73:988-994. https://doi.org/10.1016/j .theriogenology.2009.11.015.

Cheong, S. H., D. V. Nydam, K. N. Galvão, B. M. Crosier, and R. O. Gilbert. 2011. Cow-level and herd-level risk factors for subclinical endometritis in lactating Holstein cows. J. Dairy Sci. 94:762-770. https://doi.org/10.3168/jds.2010-3439.

Couto, G. B., D. H. Vaillancourt, and R. C. Lefebvre. 2013. Comparison of a leukocyte esterase test with endometrial cytology for diagnosis of subclinical endometritis in postpartum dairy cows. Theriogenology 79:103-107. https://doi.org/10.1016/j.theriogenology 2012.09.014.

de Boer, M. W., S. J. LeBlanc, J. Dubuc, S. Meier, W. Heuwieser, S. Arlt, R. O. Gilbert, and S. McDougall. 2014. Systematic review of diagnostic tests for reproductive tract infection and inflammation in dairy cows. J. Dairy Sci. 97:3983-3999. https://doi.org/10 .3168/jds.2013-7450.

Denis-Robichaud, J., and J. Dubuc. 2015a. Determination of optimal diagnostic criteria for purulent vaginal discharge and cytological endometritis in dairy cows. J. Dairy Sci. 98:6848-6855. https://doi .org/10.3168/jds.2014-9120.

Denis-Robichaud, J., and J. Dubuc. 2015b. Randomized clinical trial of intrauterine cephapirin infusion in dairy cows for the treatment of purulent vaginal discharge and cytological endometritis. J. Dairy Sci. 98:6856-6864. https://doi.org/10.3168/jds.2014-9129.

Dohoo, I., W. Martin, and H. Stryhn. 2003. Veterinary Epidemiological Research. 1st ed. AVC Inc, Charlottetown, Prince Edward Island, Canada.

Dubuc, J., T. F. Duffield, K. E. Leslie, J. S. Walton, and S. J. LeBlanc. 2010. Definitions and diagnosis of postpartum endometritis in dairy cows. J. Dairy Sci. 93:5225-5233. https://doi.org/10 .3168/jds.2010-3428.

Farver, T. B. 1987. Disease prevalence estimation in animal populations using two-stage sampling designs. Prev. Vet. Med. 5:1-20. https://doi.org/10.1016/0167-5877(87)90002-X.

Galvão, K. N., M. Frajblat, S. B. Brittin, W. R. Butler, C. L. Guard, and R. O. Gilbert. 2009. Effect of prostaglandin $F_{2 \alpha}$ on subclinical endometritis and fertility in dairy cows. J. Dairy Sci. 92:49064913. https://doi.org/10.3168/jds.2008-1984.

Gilbert, R. O., S. T. Shin, C. L. Guard, H. N. Erb, and M. Frajblat. 2005. Prevalence of endometritis and its effects on reproductive performance of dairy cows. Theriogenology 64:1879-1888. https:// doi.org/10.1016/j.theriogenology.2005.04.022.

Hammon, D. S., I. M. Evjen, T. R. Dhiman, J. P. Goff, and J. L. Walters. 2006. Neutrophil function and energy status in Holstein cows with uterine health disorders. Vet. Immunol. Immunopathol. 113:21-29. https://doi.org/10.1016/j.vetimm.2006.03.022.

Humphry, R. W., A. Cameron, and G. J. Gunn. 2004. A practical approach to calculate sample size for herd prevalence surveys. Prev. Vet. Med. 65:173-188. https://doi.org/10.1016/j.prevetmed.2004 .07 .003 .

Kasimanickam, R., T. F. Duffield, R. A. Foster, C. J. Gartley, K. E. Leslie, J. S. Walton, and W. H. Johnson. 2004a. Endometrial cytology and ultrasonography for the detection of subclinical endometritis in postpartum dairy cows. Theriogenology 62:9-23. https: //doi.org/10.1016/j.theriogenology.2003.03.001.

Kasimanickam, R., T. F. Duffield, R. A. Foster, C. J. Gartley, K. E. Leslie, J. S. Walton, and W. H. Johnson. 2004b. Endometrial cytology and ultrasonography for the detection of subclinical endo- metritis in postpartum dairy cows. Theriogenology 62:9-23. https: //doi.org/10.1016/j.theriogenology.2003.03.001.

Kaya, S., O. Merhan, C. Kacar, A. Colak, and K. Bozukluhan. 2016. Determination of ceruloplasmin, some other acute phase proteins, and biochemical parameters in cows with endometritis. Vet. World 9:1056-1062. https://doi.org/10.14202/vetworld.2016.1056-1062.

Madoz, L. V., M. J. Giuliodori, M. Jaureguiberry, J. Plöntzke, M. Drillich, and R. L. de la Sota. 2013. The relationship between endometrial cytology during estrous cycle and cutoff points for the diagnosis of subclinical endometritis in grazing dairy cows. J. Dairy Sci. 96:4333-4339. https://doi.org/10.3168/jds.2012-6269.

McDougall, S., H. Hussein, D. Aberdein, K. Buckle, J. Roche, C. Burke, M. Mitchell, and S. Meier. 2011. Relationships between cytology, bacteriology and vaginal discharge scores and reproductive performance in dairy cattle. Theriogenology 76:229-240. https:// doi.org/10.1016/j.theriogenology.2010.12.024.

McDougall, S., R. Macaulay, and C. Compton. 2007. Association between endometritis diagnosis using a novel intravaginal device and reproductive performance in dairy cattle. Anim. Reprod. Sci. 99:923. https://doi.org/10.1016/j.anireprosci.2006.03.017.

Pepe, M., G. Longton, and H. Janes. 2009. Estimation and comparison of receiver operating characteristic curves. Stata J. 9:1. https://doi .org/10.1177/1536867X0900900101.

Plöntzke, J., L. V. Madoz, R. L. De la Sota, M. Drillich, and W. Heuwieser. 2010. Subclinical endometritis and its impact on reproductive performance in grazing dairy cattle in Argentina. Anim. Reprod. Sci. 122:52-57. https://doi.org/10.1016/j.anireprosci.2010 .07 .006 .

Prunner, I., K. Wagener, H. Pothmann, M. Ehling-Schulz, and M. Drillich. 2014. Risk factors for uterine diseases on small- and medium-sized dairy farms determined by clinical, bacteriological, and cytological examinations. Theriogenology 82:857-865. https://doi .org/10.1016/j.theriogenology.2014.06.015.

Roche, J. R., P. G. Dillon, C. R. Stockdale, L. H. Baumgard, and M. J. VanBaale. 2004. Relationships among international body condition scoring systems. J. Dairy Sci. 87:3076-3079. https://doi.org/ 10.3168/jds.S0022-0302(04)73441-4.

Runciman, D. J., G. A. Anderson, and J. Malmo. 2009. Comparison of two methods of detecting purulent vaginal discharge in postpartum dairy cows and effect of intrauterine cephapirin on reproductive performance. Aust. Vet. J. 87:369-378. https://doi.org/10 $.1111 /$ j.1751-0813.2009.00469.x.

Runciman, D. J., G. A. Anderson, J. Malmo, and G. M. Davis. 2008 Effect of intrauterine treatment with cephapirin on the reproductive performance of seasonally calving dairy cows at risk of endometritis following periparturient disease. Aust. Vet. J. 86:250-258. https://doi.org/10.1111/j.1751-0813.2008.00302.x.

Sheldon, I. M., G. S. Lewis, S. LeBlanc, and R. O. Gilbert. 2006. Defining postpartum uterine disease in cattle. Theriogenology 65:1516-1530. https://doi.org/10.1016/j.theriogenology.2005.08 .021 .

Sheldon, I. M., D. E. Noakes, A. N. Rycroft, and H. Dobson. 2002. Effect of postpartum manual examination of the vagina on uterine bacterial contamination in cows. Vet. Rec. 151:531-534. https:// doi.org/10.1136/vr.151.18.531.

Thrusfield, M. 2007. Veterinary Epidemiology. 3rd Ed. ed. Blackwell Publishing, Oxford, UK.

van Smeden, M., C. A. Naaktgeboren, J. B. Reitsma, K. G. M. Moons, and J. A. H. de Groot. 2014. Latent class models in diagnostic studies when there is no reference standard-A systematic review. Am. J. Epidemiol. 179:423-431. https://doi.org/10.1093/aje/ kwt286.

\section{ORCIDS}

S. McDougall @ https://orcid.org/0000-0002-9865-0532

A. Bates ๑ https://orcid.org/0000-0003-0732-4262

C. R. Burke @ https://orcid.org/0000-0003-3868-8675 